\title{
Social and Technical Readiness for a Telehealth Assessment Service for Adults With Complex Wheelchair and Seating Needs: A National Survey of Stakeholders
}

Fiona Graham BOccTher, PhD

Senior Lecturer, Rehabilitation Teaching and Research Unit, University of Otago, Wellington, New Zealand

Pauline Boland BSC (Hons) OT, MHealSci (Rehabilitation), PhD

School of Allied Health and Aging Research Centre, Health Research Institute, University of Limerick, Republic of Ireland

Sally Wallace BOccTher, PGDip Rehabilitation

Professional Advisor, Enable New Zealand, Wellington and Wairarapa, New Zealand

William J. Taylor $M B C h B, P h D$

Rheumatologist and Rehabilitation Physician, and Associate Professor, Rehabilitation Teaching and Research Unit, University of Otago, Wellington, New Zealand

Bernadette Jones MPH

Senior Research Fellow, Department of Medicine, University of Otago, Wellington, New Zealand; Co-director, Foundation for Equity \& Research, New Zealand

Jasjot Maggo MPhil

Research Assistant, Rehabilitation Teaching and Research Unit, University of Otago, Wellington, New Zealand

Rebecca Grainger BMedSci, MB ChB, PhD

Rheumatologist and Associate Professor, Rehabilitation Teaching and Research Unit, University of Otago, Wellington, New Zealand

\section{ABSTRACT}

Wheelchairs can significantly improve quality of life for those who need them, yet access to physiotherapists or occupational therapists specialising in wheelchair and seating assessment can be difficult, especially for Māori. This paper reports on a national online survey that was undertaken as phase 1 of a mixed methods study of key stakeholders of the perceived social and technical requirements of a telehealth wheelchair assessment service for people with complex mobility needs. Key stakeholders included wheelchair users and their families, specialist and non-specialist assessors, technicians, and service managers. Responses $(n=$ 114 ) indicated perceived shortcomings with current in-person assessment. Telehealth assessment was anticipated to improve service quality, particularly the timeliness of services (52/92, 57\%) and prioritisation of the urgency of assessment (71/92, 77\%). Preferences were for use of existing software rather than bespoke systems. Training in conducting assessment via telehealth was considered essential by most assessors (29/41, 71\%). Internet connectivity was in place for most wheelchair users (43/47, 92\%) but was inadequate for 29\% (14/49) of assessors (pre-COVID-19). Māori wheelchair users largely had infrastructure in place for telehealth assessment $(10 / 11,91 \%)$ and held positive expectations of it. Telehealth wheelchair and seating assessment is anticipated to improve the quality of care for wheelchair users with complex needs. Upgraded technical capability of public health services and robust training in conducting assessment via telehealth will be critical to successful uptake of this service. Specific needs for Māori wheelchair users warrant further investigation.

Graham, F., Boland, P., Wallace, S., Taylor, W. J., Jones, B., Maggo, J. \& Grainger, R. (2021). Social and technical readiness for a telehealth assessment service for adults with complex wheelchair and seating needs: A national survey of stakeholders. New Zealand Journal of Physiotherapy, 49(1), 31-39. https://doi.org/10.15619/NZJP/49.1.05

Key Words: Indigenous Peoples, New Zealand, Seating, Telerehabilitation, Wheelchairs

\section{INTRODUCTION}

Wheelchairs are one of the most used and highly valued assistive devices for people who require them for personal mobility (Boland et al., 2018), and with mobility a central concern of physiotherapists (Wikström-Grotell \& Eriksson, 2012). Welldesigned and carefully fitted wheelchairs and integrated seating systems are often essential for inclusion and participation in society for people with mobility-related disabilities (World Health
Organization, 2008). Wheelchairs can rapidly enable a person to achieve their mobility goals, maintain employment (Minis et al., 2014), and alleviate pain (Hunt et al., 2016). Yet, despite this, the disability community reports widespread unmet needs for adaptive equipment, including wheelchairs, both internationally (World Health Organization, 2020) and within New Zealand, where unmet need is substantially higher for Māori compared to non-Māori (Health Quality and Safety Commission, 2019). 
Wheelchair and seating provision is publicly funded in New Zealand through either the Ministry of Health $(\mathrm{MOH})$ or the Accident Compensation Corporation (ACC) for accident-related wheelchair needs. ACC is a compulsory national insurance scheme administered by the New Zealand Government. Criteria for funding and the funding scope differs between these two entities. It is unclear if these differences impact on varying levels of current service satisfaction.

For people with neuromuscular health conditions (NMC), wheelchair and seating assessments are often "complex", given progressive changes in multiple body functions of wheelchair users, and variable physical, social, and economic environments (De Souza \& Frank, 2016). NMC include conditions such as muscular dystrophies and motor neuron disease, and traumatic origins, such spinal cord injury. To optimise seating and/or wheelchair configurations, complex wheelchair assessments involve interviewing wheelchair users about their goals; taking accurate measurements of their body position; the evaluation of their home, community and/or work environments; and extensive product knowledge (Borg et al., 2012; Martin et al, 2011; Rousseau-Harrison \& Rochette, 2013). Complex wheelchair assessments require the skills of highly specialised assessors (physiotherapists or occupational therapists) with advanced clinical training. Regular, ongoing application of assessment skills is widely recognised as critical to maintaining competence in complex wheelchair assessments, given the complex clinical reasoning required and continually evolving product solutions. Consequently, in New Zealand where both population (5 million) and population density $\left(14: 1 \mathrm{~km}^{2}\right.$ ) (Stats $\mathrm{NZ}, 2020$ ) are relatively low, specialist assessors are few and located in urban centres. In New Zealand, complex assessments typically occur in wheelchair users' homes or workplaces, with significant others present, and with a local non-specialist therapist accompanying the remote specialist assessor. Alternatively, wheelchair users travel to regional specialist clinics. Access to specialist assessors is, therefore, a substantial barrier to timely wheelchair assessment for people with complex needs. Travel to specialist clinics is difficult for many people with NMC, given the associated fatigue and expense of travel. A telehealth wheelchair assessment service (TWAS) for people with complex wheelchair and seating needs may provide a more timely and accessible service than in-person services.

TWAS involves the use of technology (e.g., video-conferencing) to connect a wheelchair-user and local non-specialist therapist with a remote specialist assessor. Bespoke and software-as-aservice (SaaS) systems have been proposed previously for TWAS (Graham et al., 2019), varying considerably in cost, functionality, bandwidth and device requirements, data privacy, and security functions. In New Zealand, various SaaS technologies have been used in an ad hoc manner with anecdotal success. TWAS was the exception rather than the rule until non-contact servicing was required to reduce the risk of community transmission of COVID-19, prompting the rapid switch to telehealth solutions. However, there remains no national policy, training, or infrastructure to support safe and widespread use of TWAS, and there is limited international research or sector-specific information on which to robustly plan for such a service.
Our scoping review on the perceptions and use of TWAS and evidence of its effectiveness has identified that studies to date are limited and of low methodological quality (Graham et al., 2019). Findings from non-randomised, case-controlled studies indicate that TWAS can be cost-effective, with clinical outcomes equivalent to in-person assessment by trained assessors (Barlow et al., 2009; Schein, Schmeler, Holm et al., 2010). Satisfaction with TWAS is generally high for wheelchair users (Barlow et al., 2009). Most significantly, TWAS facilitated access to services for wheelchair users when travel to assessment services was not possible (Schein, Schmeler, Saptono et al., 2010). While time efficiencies and some educational advantages have been reported, many therapists are hesitant to adopt TWAS, citing concerns about clinical errors (Atwa et al., 2013; Khoja et al., 2005). It is unclear if this concern reflects a broader anxiety about change to clinical practice when adopting technology or a warranted concern about clinical risk. No studies to date have specifically examined the effect of TWAS for people with complex wheelchair needs, who have the most to gain from appropriate and timely assessment, and specialist equipment provision. Nor have prior studies explored the perspectives of minority and/or indigenous populations, who may have distinct needs.

Constructs, such as health, disability, and participation in society, which are known to vary in meaning between cultures (Bickenbach, 2009; Cram et al., 2003, Washbourn et al., 2016), are critical to a successful match of wheelchair users with wheelchair technology solutions (MacLachlan \& Scherer, 2018). Differences in unmet needs for adaptive equipment for Māori compared to non-Māori (Health Quality and Safety Commission, 2019) indicate the reality of these cultural distinctions. Therefore, New Zealand specific research is needed to inform TWAS delivery that is clinically safe, optimised for service efficiency, appropriate for people with complex wheelchair needs, and most importantly, is designed to address health inequities that exist for Māori and people with disabilities.

Change of service delivery has historically often occurred without due consideration of implications and potential unintended consequences (Sligo et al., 2017). Significant changes, like moving from in-person to remote, video-based care, will require careful implementation to ensure success. Social and technical factors (Sittig \& Singh, 2010) underpin the success of end user uptake of new technologies. Social factors that influence the adoption of technology include personal, professional and organisational culture. Technical factors include the software and hardware requirements of a system. According to the universal theory of acceptance and use of technology (Venkatesh \& Davis, 2000), key social factors that determine the adoption of new technology include perceived ease of use and perceived usefulness (Davis, 1986). Expectations of effort (e.g., to learn a new system), social influences (e.g., perceived competence by peers), and facilitating conditions (i.e., technology functions that enhance ease of use) (Venkatesh et al, 2003) further explain technology uptake and enhance the likelihood of technology adoption when considered and addressed in early design stages. This study sought stakeholders' perceptions of the social (e.g., perceived ease of use and 
perceived usefulness) and technical facilitating conditions (e.g., hardware, software, and other infrastructural resources), with particular analysis of the culturally specific needs of Māori. To understand the context of these perspectives, stakeholders' satisfaction with the current system was first established. Specifically, the research questions were:

1. How satisfied are stakeholders with current in-person wheelchair and seating services?

2. What are the anticipated social and technical requirements of TWAS from the perspectives of wheelchair users with NMC; specialist and non-specialist assessors; and managers, funders and policy developers?

3. What are the culturally specific perspectives and needs of Māori wheelchair users with NMC of TWAS?

\section{METHODS}

\section{Design}

A survey method was the first phase of a two-phase convergent (quan-QUAL) mixed methods study (Creswell \& Plano Clark, 2011) to determine the socio-technical design requirements for TWAS in New Zealand. Survey methods enabled maximal reach in identifying the socio-technical landscape of stakeholders of TWAS and informing the data collection for a subsequent qualitative study. Ethical approval was obtained from the University of Otago Ethics Committee (Health) (reference number H19/046) alongside locality approval and Māori consultation from each recruitment site. The study was guided by regular discussions with an advisory group comprising Māori, wheelchair users, physiotherapists, allied health students and educators, and technology specialists.

Participants were eligible to be included if they had been involved in complex wheelchair assessment (in-person or via telehealth) within the last 2 years, or were currently involved in the management, funding or design of wheelchair services. This included wheelchair users aged $>18$ years with NMC (Morrison, 2016); specialist or non-specialist (i.e., local to the wheelchair user) assessors, including technicians and service managers; and carers and significant others if they were present at a complex wheelchair and seating assessment within the last 2 years. Wheelchair users were included if they self-reported a wheelchair as their main means of mobility inside the home. This was used as an indicator of "complexity", on the basis that if people with NMC require a wheelchair for indoor mobility, their wheelchair mobility needs will involve physical, social, and environmental assessment consistent with definitions of "complex" as described in the introduction.

\section{Exclusion criteria}

We excluded children and youth $<18$ years because we felt that they and their families would have a distinctive and different set of needs.

\section{Recruitment}

Invitations were distributed electronically to all publicly funded health authorities that approved study participation (13/20), and 11 independent consumer and professional organisations. The sampling frame could not be determined because of privacy concerns from district health boards. The survey was distributed using the REDCap platform (Harris et al., 2009) via a hyperlink in an email to each organisation. Study invitations were then disseminated using the communication systems already in place (i.e., email, social media, and printed newsletters) for each organisation. Māori participation was encouraged by targeting health authorities in regions with high Māori populations.

\section{Instruments}

Data collection tools included a survey and, for wheelchair users, the Quebec User Evaluation of Satisfaction with Technology (QUEST) (Demers et al., 2002), discussed below. Survey design was informed by the socio-technical health information technology model (Sittig \& Singh, 2010) and the universal theory of acceptance and use of technology model. Questions informed by the socio-technical health information technology model asked respondents about the expected effort involved with and benefit of using TWAS, and social influences on expected uptake (including personal, professional and organisational culture). Survey questions ( $n$ = 20) also included a Likert rating (e.g., degree of necessity, importance, or confidence), categorical choice (e.g., preferred hardware features), and yes/no questions (e.g., prior use of telehealth), resulting in ordinal and categorical data. The survey was refined through multiple iterations of cognitive interviewing (Willis, 2005) with members of each stakeholder group drawn from co-authors and advisory group members $(n=13)$, including Māori $(n=2)$ and wheelchair users ( $n=$ 2). Wording was modified slightly for each stakeholder group to reflect the context of their engagement in wheelchair and seating assessment. Demographic questions for all stakeholders included age (years), gender, (male/female/gender diverse), ethnicity (as per New Zealand Census ethnicity options), years of involvement in wheelchair and seating assessment, and a self-identified stakeholder category. Additional questions for consumers related to their health, educational and employment status; and the type of wheelchair they used. Questions which directly addressed the research questions in this study were: the perceived impact of TWAS on quality and efficiency of care, and confidence; training needs (in relation to undertaking TWAS); and the technical (software and hardware) requirements of TWAS. The full survey is available from the corresponding author upon request.

To provide further context to the responses of wheelchair users, the QUEST was embedded within the survey to indicate current wheelchair and service satisfaction. The QUEST is a 12 -item self-reported measure of consumer satisfaction with assistive technology ( 8 items) and services ( 4 items), indicated on a 5-point Likert scale. The QUEST has been widely validated (Demers et al., 2002) and is considered the gold standard for the measure of assistive technology satisfaction. Service-related questions do not specify the mode of service delivery (in-person or tele-delivered), and thus are applicable to both/either modes.

Data collection and analysis

Survey responses were entered into REDCap by participants (June-September 2019, pre-COVID-19) and analysed using SPSS V25 (IBM Corp, 2013) and R, version 4.0 (R Core Team, 2018) using descriptive statistics. Surveys with one or more responses 
were included in the analysis, hence specific response numbers (n) are reported per question. QUEST findings and questions relating to the impact on care are presented as stacked horizontal bar charts. Categories of less than five participants are reported in text only.

\section{RESULTS}

Surveys ( $n=114$ ) were returned by wheelchair users ( $n=47)$; assessors ( $n=49$ ), comprising occupational therapists ( $n=$ 39) and physiotherapists ( $n=10)$; family members $(n=9)$; technicians $(n=6)$; and service managers $(n=3)$. No funders or policy developers responded. Complete responses were received for 84 surveys. Where an item/question response was incomplete, the denominator may be less than the number of respondents in the stakeholder category.

Most respondents were female $(66 / 90,73 \%)$, identifying as New Zealand European (77/94, 82\%), with half aged between 46 and 65 years (51/99, 52\%). Responses from Māori (11/94, $12 \%$ ) reflected less than population proportions of Māori with disability (Stats NZ, 2013) (Table 1). Most Māori participants were wheelchair users (7/11, 64\%). Respondents represented all geographic regions of New Zealand. For the 36 wheelchair users who reported their wheelchair funding source, 72\% (26/36) were funded by the $\mathrm{MOH}, 19 \%(7 / 36)$ by $\mathrm{ACC}$, and $8 \%(3 / 36)$ privately.
Education level was high among wheelchair users, with over half $(25 / 47,53 \%)$ having postgraduate or tertiary qualifications. Wheelchair users' general health was high with only $6 \%(3 / 47)$ reporting poor health. Only 28\% (13/47) of wheelchair users were in paid employment and $12 \%(6 / 47)$ were able to drive themselves to hospital appointments. Most wheelchair users $(31 / 47,66 \%)$ were less than 60 min drive from their nearest major hospital.

About half of wheelchair users (25/47, 53\%) used a powered wheelchair and had used a wheelchair for more than 2 years, indicating significant levels of physical disability and considerable experience with current wheelchair assessment services; 18 wheelchair users had experienced greater than nine assessments.

Just over half of wheelchair users reported being "quite" to "very satisfied" with their current wheelchairs and recent wheelchair services (see QUEST responses in Figure 1). Patterns in satisfaction with wheelchairs and services were similar irrespective of the wheelchair funder or ethnicity of the user. Many wheelchair users reported waiting more than 6 months for their first wheelchair $(14 / 37,38 \%)$, with one in five (8/37, $22 \%$ ) waiting longer than 12 months. Proportions were similar for reviews of wheelchairs. In contrast, most assessors estimated that the first wheelchairs and reviews were in place within 1 to 6 months $(33 / 41,81 \%)$.

\section{Table 1}

Participant Demographics $(n=114)$

\begin{tabular}{|c|c|c|c|}
\hline Characteristics & $\begin{array}{c}\text { Wheelchair users } \\
n\end{array}$ & $\begin{array}{c}\text { Assessors } \\
n\end{array}$ & $\begin{array}{c}\text { All } \\
n(\%)\end{array}$ \\
\hline Age (years) & - & - & $99^{a}$ \\
\hline $16-25$ & 4 & 9 & $13(9)$ \\
\hline $26-35$ & 4 & 1 & $6(6)$ \\
\hline $36-45$ & 4 & 4 & $15(15)$ \\
\hline $46-55$ & 11 & 16 & $28(28)$ \\
\hline $56-65$ & 6 & 14 & $23(23)$ \\
\hline$>66$ & 7 & 5 & $14(14)$ \\
\hline Gender & - & - & $90^{a}$ \\
\hline Male & 15 & 1 & $21(23)$ \\
\hline Female & 19 & 38 & $66(73)$ \\
\hline Gender diverse & 2 & 1 & $3(3)$ \\
\hline Ethnicity ${ }^{b}$ & - & - & $94^{a}$ \\
\hline NZE & 29 & 36 & $77(82)$ \\
\hline Māori & 7 & 2 & $11(12)$ \\
\hline Pacifica & 2 & 1 & $3(3)$ \\
\hline Other & 1 & 1 & $3(3)$ \\
\hline Total & 47 & 49 & - \\
\hline
\end{tabular}

Note. NZE = New Zealand European.

a Sample size varies due to missing data from some participants; ${ }^{\text {b }}$ More than one ethnicity could be selected. 


\section{Figure 1}

QUEST Items From Wheelchair Users $(n=47)$

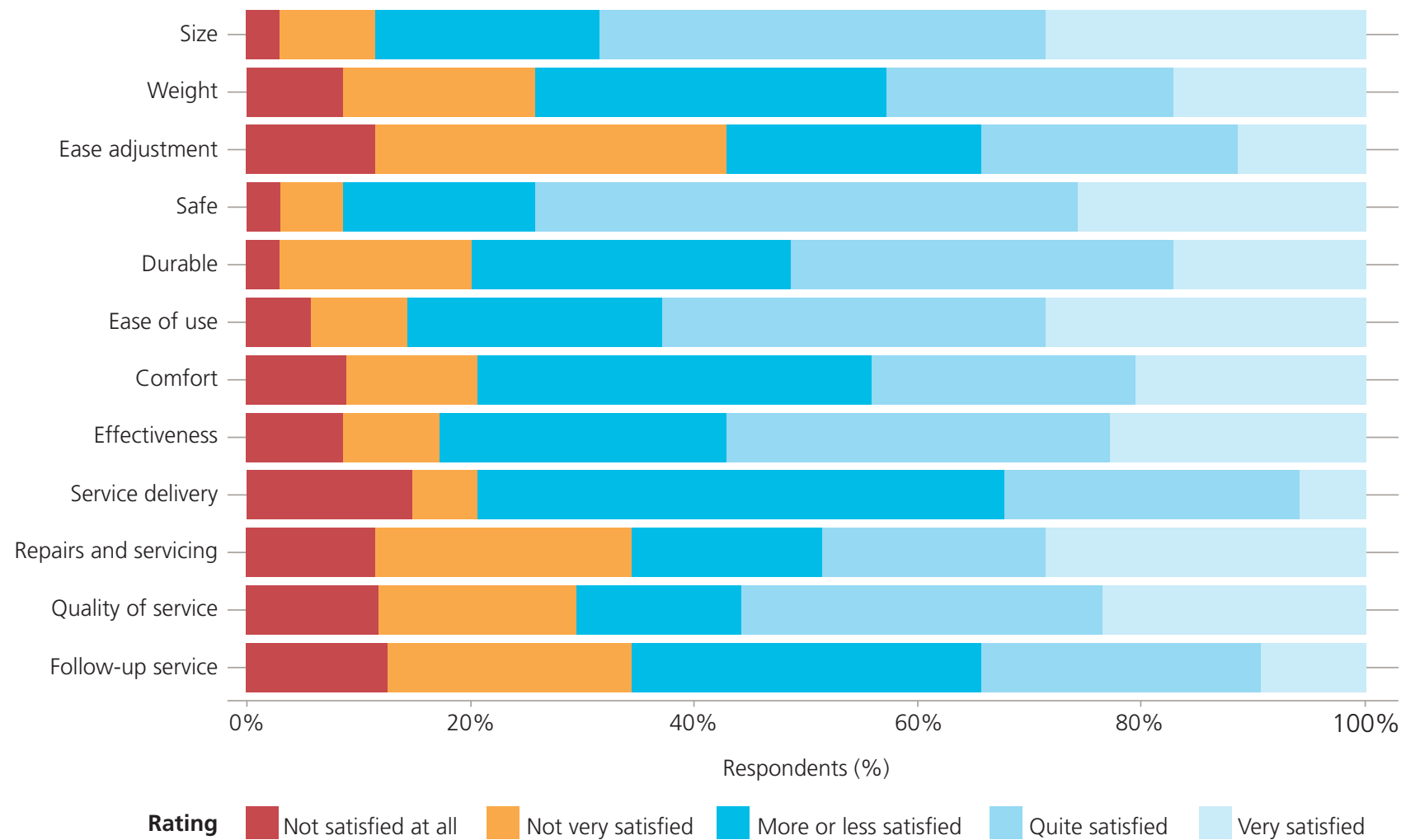

Positive expectations of TWAS were indicated across all stakeholder groups, and related to reducing the timeframe from a wheelchair user's service request to their needs being met (52/92, 57\%), addressing wheelchair user priorities (67/91, $74 \%)$, enabling wheelchair user participation in activities and spaces they valued $(62 / 92,67 \%)$, prioritisation of the urgency of assessment $(71 / 92,77 \%)$, and minimising travel time for health professionals (86/92, 94\%) and wheelchair users (79/92, $86 \%$ ) (see Figure 2). The potential of TWAS to support return of unwanted equipment was viewed positively by most wheelchair users $(26 / 37,70 \%)$ and managers $(n=2 / 3)$, but only a minority of assessors (14/41, 34\%). The most positive expectations of TWAS were consistently from wheelchair users, with perceived negative impacts reported by less than five participant responses across all areas and stakeholders. While acknowledging the small and unequal sample size for Māori, non-Māori wheelchair users tended to have a somewhat more optimistic perception of the impact of telehealth assessment compared to Māori for most (5/9) aspects of care.

Confidence in the ability to learn to use TWAS was high and evenly spread across stakeholders (including Māori and nonMāori), with $88 \%(80 / 91)$ of respondents indicating moderate to high levels of confidence. In contrast, stakeholders varied in their belief in the need for training in a TWAS system, with over $70 \%(29 / 41)$ of assessors indicating training was very necessary, compared to only $22 \%$ (8/37) of wheelchair users.

Internet access in the location TWAS was anticipated to occur was in place for only 57\% (54/95) of stakeholders and 29\%
(14/49) of assessors, but 91\% (10/11) of Māori and 92\% (43/47) of wheelchair users. When internet was available, sufficient connectivity for video-conferencing "without freezing" was "usually/always" in place for $91 \%$ (41/45) of wheelchair users and $71 \%$ (32/45) of assessors. Payment for internet use for TWAS by service providers was considered essential by only $23 \%(16 / 69)$ of all stakeholders, and 30\% (3/11) of Māori.

Internal system features considered most important to assessors, technicians, and managers related to compatibility with existing systems, such as the ability to share or transfer files (43/44, 98\%). Views were mixed about features which guided clinical data collection. For example, structured clinical information gathering was seen as important by many (38/44, $86 \%)$, whereas more directive cues, such as alerts for missing information (28/44, 68\%) and checklists for treatment options (18/44, 41\%), were viewed less favourably, particularly by assessors. System security and confidentiality was absolutely important to all assessors and managers, but to only $76 \%$ (34/45) of wheelchair users.

Key hardware features considered important for all stakeholders were portability, camera reversal, and photo/video saving capability. Other features, such as onscreen measurement tripods, eye-gaze control, and voice activation, were considered important by very few. All assessors had access to at least one type of device that they could use to undertake a TWAS (smartphone, tablet, laptop and/or personal computer). But only $47 \%$ (22/47) of wheelchair users and 55\% (6/11) of Māori had access to tablets, the device considered ideal by most. 


\section{Figure 2}

Assessor and Wheelchair User Perceived Impact of Telehealth Wheelchair Assessment Service on Nine Areas of the Quality of Care
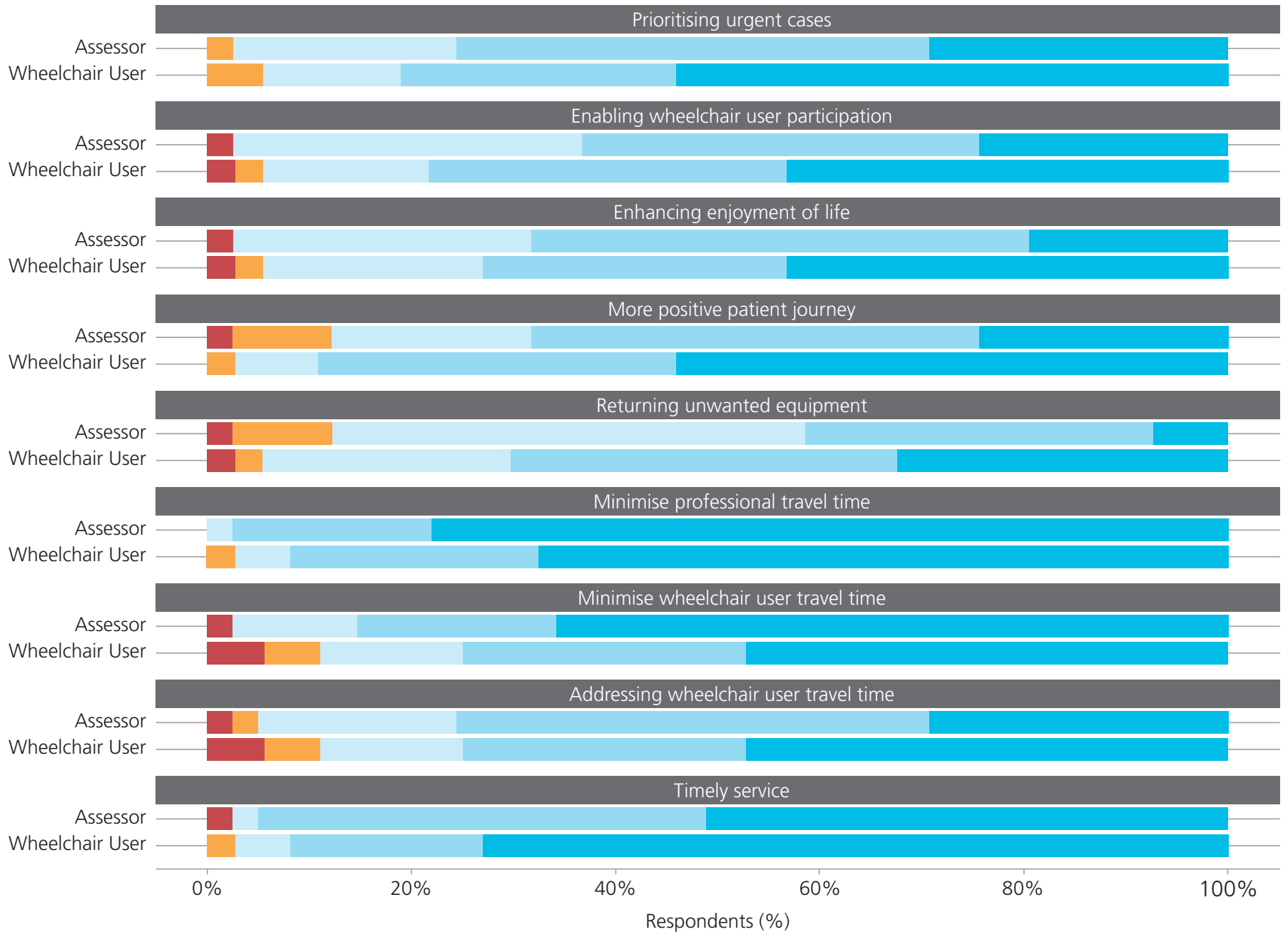

Rating Big negative impact $\quad$ Small negative impact $\quad$ No impact $\quad$ Small positive impact $\quad$ Big positive impact

\section{DISCUSSION}

This study explored the social and technical design requirements for a telehealth wheelchair service for people with complex wheelchair and seating needs. Particular attention was paid to end-user acceptance of telehealth technology and the needs of Māori.

The modest level of satisfaction with current in-person wheelchair and seating assessment for people with complex mobility needs, particularly among wheelchair users and their family members, suggests a context of readiness to try alternative delivery formats, such as TWAS. Although the time taken to receive a wheelchair and seating solution that met mobility needs appeared to drive much of this dissatisfaction for all stakeholders, there was also only modest satisfaction from wheelchair users with the resulting wheelchair product, which is at odds with patterns internationally for people with
NMC (Ward et al., 2010). TWAS as an alternative to in-person assessment was perceived to improve the timeliness of services, access to services, and other patient outcomes, but only moderately (see Figure 2); telehealth was not viewed by any stakeholder group as a panacea to current service issues, least of all by Māori.

The perceived usefulness of TWAS, an important criterion for the acceptance and uptake of new technology, appears to be high among all participant groups. Although the majority of stakeholders were confident in being able to learn to use technology for this purpose, the desire for training in TWAS among assessors was widely expressed and is, therefore, an important socio/human related requirement to its successful implementation. Prior research indicates that training for TWAS is likely to require clinical skills in the core elements of wheelchair assessment for tele-delivery, instruction in the safe 
use of technology (Edirippulige \& Armfield, 2017; Graham et al., 2019), and for this specific population, a non-threatening learning environment (Jang-Jaccard et al., 2014).

Surprisingly, anticipated technology preferences were for simple SaaS products (e.g., Zoom, Facetime) when undertaking TWAS assessments. Ease of use (and ease of learning) were prioritised over bespoke functionality, such as on-screen measurement. Compatibility with existing record keeping and communication systems appeared to be prioritised over system functionality, such as internal note keeping options. Assessors' preference appeared to be an in-person assistant, such as a local therapist or family member, rather than highly specialised technical functions.

Preferred devices for wheelchair users appeared to be a tablet or smartphone, for their portability. Overall, it appeared that the hardware requirements for TWAS were in place for most stakeholders. Conversely, software infrastructure essential to telehealth, such as reliable internet connectivity, was not available to almost $30 \%$ of assessors. While this may have changed after COVID-19 response initiatives, if unresolved, this poses a substantial limitation on the capacity of the New Zealand public health service to deliver TWAS. These findings provide critical information to meet our United Nations member state obligations to develop and implement policies and programmes that improve access to assistive technologies that meet health and disability needs (World Health Organization, 2018).

\section{Limitations}

The categorical and numerical nature of survey questions limit understanding of participants' rationale for their responses. Further qualitative enquiry (phase 2 of the wider mixed methods study) is important to understand the dissatisfaction with current services and design components of TWAS. The extent of missing responses for some items may also confer a bias, particularly for wheelchair users. While forced response features could in future be enabled on the electronic survey, it is noteworthy that the greatest non-response related to demographic information, indicating that there may have been a perception from some wheelchair users that anonymity was a risk if they completed all demographic questions.

While several strategies were in place to encourage participation of Māori in this study, the percentage recruited (12\%) fell short of population levels of Māori with disabilities (26\%), thus interpretation of findings for Māori should be undertaken with care. Most Māori were wheelchair users; responses for these two groups are closely related. Education levels were high among wheelchair users, thus their views may not accurately represent those of the wider wheelchair user population.

Recruitment of non-specialist (level 1) assessors was low. Level 1 assessors are often regionally based and may have different infrastructure available. They also have dual roles in TWAS as rehabilitation provider and learner, when assessing jointly with specialist assessors. Garnering their willingness to engage in TWAS and identifying their preparation needs will be an important factor in its success. Similarly, recruitment of physiotherapists as assessors was low. While service user responses about their satisfaction with wheelchair assessment services related to all health professionals, physiotherapists' perspectives on the requirements of TWAS will be critical to its success, given their distinctive contribution to wheelchair assessment and the current advocacy for team assessment of assistive technology needs (Smith et al., 2018). No funders or policy developers could be recruited to this study. Their perspective on key design features of TWAS will be critical to the purchasing and roll out of such a service.

COVID-19 instigated physical distancing measures in New Zealand during 2020; this resulted in substantial unplanned and fluctuating changes to the use of telehealth in assessment of wheelchair and seating needs, and resulted in other disruptions to service delivery, such as the ceasing of some services for several months. It is unclear how these social, funding and service delivery changes might impact on the social and technical requirements of TWAS in New Zealand or how longterm such changes will be.

\section{CONCLUSION}

This study examined the social and technical requirements of a telehealth wheelchair and seating assessment service, as perceived by wheelchair users, their family members, assessors, managers, Māori, and non-Māori pre COVID-19 social distancing initiatives. Telehealth assessment was largely viewed as valuable and a means to positively impact the quality of service delivery and wider health outcomes by all stakeholders. The technical requirements for tele-assessment of wheelchairs are in place for the majority but may need upgrading for some assessors. Assessor training in telehealth assessment will be critical to widespread uptake.

\section{KEY POINTS}

1. A telehealth wheelchair and seating assessment service (TWAS) for people with complex wheelchair and seating needs is widely supported by both wheelchair users and health professionals, and is viewed by many as a way to address some of the shortcomings of the current service design.

2. Length of time to provision of wheelchair solutions is a shortcoming of the current in-person assessment system that all stakeholders expect to change through TWAS

3. Robust training in use of a TWAS will be critical to its successful uptake among health professionals, for both specialist and non-specialist assessors.

4. Māori wheelchair users and assessors welcome a TWAS, and are equipped with the devices and internet access as equally as non-Māori, yet are more conservative in their expectations that TWAS will address current service issues.

\section{DISCLOSURES}

This study was funded by the Neuromuscular Research Fund of New Zealand $(\$ 18,000)$. There are no conflicts of interest which may be perceived to interfere with or bias this study. 


\section{PERMISSIONS}

This study was approved by the University of Otago Ethics Committee (Health) (reference number \#H19/046). Informed consent was provided by all participants prior to participation in the study.

\section{ACKNOWLEDGEMENTS}

We wish to acknowledge assistance from Dr. Jonathan Williman, University of Otago Christchurch, in assisting with the data analysis and presentation for this study.

\section{ADDRESS FOR CORRESPONDENCE}

Dr. Fiona Graham, University of Otago, Wellington.

Email: fiona.graham@otago.ac.nz

\section{REFERENCES}

Atwa, A., Money, A. G., Spiliotopoulou, G., \& Mcintyre, A. (2013). Occupational therapists' perceptions about the clinical utility of the 3D interior design software. Disability and Rehabilitation: Assistive Technology, 8(4), 348-355. https://doi.org/10.3109/17483107.2012.713437

Barlow, I. G., Liu, L., \& Sekulic, A. (2009). Wheelchair seating assessment and intervention: A comparison between telerehabilitation and face-to-face service. International Journal of Telerehabilitation, 1(1), 17-28. https://doi. org/10.5195/ijt.2009.868

Bickenbach, J. E (2009). Disability, culture and the UN convention. Disability and Rehabilitation, 31(14), 1111-1124. https://doi. org/10.1080/09638280902773729

Boland, P., Levack, W., Graham, F., \& Perry, M. A. (2018). User perspective on receiving adaptive equipment after stroke: A mixed-methods study. Canadian Journal of Occupational Therapy, 85(4), 297-306. https://doi org/10.1177/0008417418800834

Borg, J., Larsson, S., Östergren, P. O., Rahman, A. S., Bari, N., \& Khan, A. H. (2012). User involvement in service delivery predicts outcomes of assistive technology use: A cross-sectional study in Bangladesh. BMC Health Services Research, 12, 330. https://doi.org/10.1186/1472-6963-12-330

Cram, F., Smith, L., \& Johnstone, W. (2003). Mapping the themes of Māori talk about health. New Zealand Medical Journal, 116(1170), 1p following U353.

Creswell, J. W., \& Plano Clark, V. L. (2011). Choosing a mixed methods design. In J. W. Creswell \& V. L. Plano Clark (Eds.), Designing and conducting mixed methods research (2nd ed., pp. 53-106). Sage.

Davis, F. (1986). A technology acceptance model for empirically testing new end-user information systems: Theory and results. [Doctoral dissertation]. Massachusetts Institute of Technology. https://hdl.handle. net/1721.1/15192

De Souza, L. H., \& Frank, A. O. (2016). Rare diseases: Matching wheelchair users with rare metabolic, neuromuscular or neurological disorders to electric powered indoor/outdoor wheelchairs (EPIOCs). Disability and Rehabilitation, 38(16), 1547-1556. https://doi.org/10.3109/09638288.20 15.1106599

Demers, L., Weiss-Lambrou, R., \& Ska, B. (2002). The Quebec User Evaluation of Satisfaction with Assistive Technology (QUEST 2.0): An overview and recent progress. Technology and Disability, 14(3), 101-105. https://doi. org/10.3233/TAD-2002-14304

Edirippulige, S., \& Armfield, N. (2017). Education and training to support the use of clinical telehealth: A review of the literature. Journal of Telemedicine and Telecare, 23(2), 273-282. https://doi. org/10.1177/1357633X16632968

Graham, F., Boland, P., Grainger, R., \& Wallace, S. (2019). Telehealth delivery of remote assessment of wheelchair and seating needs for adults and children: A scoping review. Disability and Rehabilitation, 42(24), 35383548. https://doi.org/10.1080/09638288.2019.1595180
Harris, P. A., Taylor, R., Thielke, R., Payne, J., Gonzalez, N., \& Conde, J. G. (2009). Research electronic data capture (REDCap) - a metadata-driven methodology and workflow process for providing translational research informatics support. Journal of Biomedical Informatics, 42(2), 377-381. https://doi.org/10.1016/j.jbi.2008.08.010

Health Quality and Safety Commission. (2019). A window on the quality of Aotearoa New Zealand's health care 2019: A view on Māori health equity. https://www.hqsc.govt.nz/assets/Health-Quality-Evaluation/PR/ Window_2019_web_final.pdf

Hunt, A., Carter, B., Abbott, J., Parker, A., Spinty, S., \& DeGoede, C. (2016) Pain experience, expression and coping in boys and young men with Duchenne muscular dystrophy - A pilot study using mixed methods. European Journal of Paediatric Neurology, 20(4), 630-638. https://doi. org/10.1016/j.ejpn.2016.03.002

Jang-Jaccard, J., Nepal, S., Alem, L., \& Li, J. (2014). Barriers for delivering telehealth in rural Australia: A review based on Australian trials and studies. Telemedicine and e-Health, 20(5), 496-504. https://doi. org/10.1089/tmj.2013.0189

Khoja, S., Casebeer, A., \& Young, S. (2005). Role of telehealth in seating clinics: A case study of learners' perspectives. Journal of Telemedicine and Telecare, 11(3), 146-149. https://doi.org/10.1258/1357633053688750

MacLachlan, M., \& Scherer, M. J. (2018). Systems thinking for assistive technology: A commentary on the GREAT summit. Disability and Rehabilitation: Assistive Technology, 13(5), 492-496. https://doi.org/10.10 80/17483107.2018.1472306

Martin, J. K., Martin, L. G., Stumbo, N. J., \& Morrill, J. H. (2011). The impact of consumer involvement on satisfaction with and use of assistive technology. Disability and Rehabilitation: Assistive Technology, 6(3), 225242. https://doi.org/10.3109/17483107.2010.522685

Minis, M. A. H., Satink, T., Kinébanian, A., Engels, J. A., Heerkens, Y. F., Van Engelen, B. G. M., \& Nijhuis-Van Der Sanden, M. W. (2014). How persons with a neuromuscular disease perceive employment participation: A qualitative study. Journal of Occupational Rehabilitation, 24(1), 52-67. https://doi.org/10.1007/s10926-013-9447-8

Morrison, B. M. (2016). Neuromuscular diseases. Seminars in Neurology, 36(5), 409-418. https://doi.org/10.1055/s-0036-1586263

Rousseau-Harrison, K., \& Rochette, A. (2013). Impacts of wheelchair acquisition on children from a person-occupation-environment interactional perspective. Disability and Rehabilitation: Assistive Technology, 8(1), 1-10. https://doi.org/10.3109/17483107.2012.670867

Schein, R. M., Schmeler, M. R., Holm, M. B., Saptono, A., \& Brienza, D. M. (2010). Telerehabilitation wheeled mobility and seating assessments compared with in person. Archives of Physical Medicine and Rehabilitation, 91(6), 874-878. https://doi.org/10.1016/j.apmr.2010.01.017

Schein, R. M., Schmeler, M. R., Saptono, A., \& Brienza, D. (2010). Patient satisfaction with telerehabilitation assessments for wheeled mobility and seating. Assistive Technology, 22(4), 215-222. https://doi.org/10.1080/104 00435.2010 .518579

Sittig, D. F., \& Singh, H. (2010). A new sociotechnical model for studying health information technology in complex adaptive healthcare systems. BMJ Quality \& Safety, 19(Suppl 3), i68-i74. https://doi.org/10.1136/ qshc.2010.042085

Sligo, J., Gauld, R., Roberts, V., \& Villa, L. (2017). A literature review for large-scale health information system project planning, implementation and evaluation. International Journal of Medical Informatics, 97, 86-97. https://doi.org/10.1016/j.ijmedinf.2016.09.007

Smith, E. M., Gowran, R. J., Mannan, H., Donnelly, B., Alvarez, L., Bell, D., Contepomi, S., Ennion, L., Hoogerwerf, E-J., Howe, T., Jan, Y-K., Kagwiza, J., Layton, N., Ledgerd, R., MacLachlan, M., Oggero, G., Pettersson, C., Pousada, T., Scheffler, E., \& Wu, S. (2018). Enabling appropriate personnel skill-mix for progressive realization of equitable access to assistive technology. Disability Rehabilitation: Assistive Technology, 13(5), 445-453. https://doi.org/10.1080/17483107.2018.1470683

Stats NZ. (2013). Disability survey 2013. https://www.stats.govt.nz/ information-releases/disability-survey-2013 
Stats NZ. (2020). Population. https://www.stats.govt.nz/topics/population

Venkatesh, V., \& Davis, F. (2000). A theoretical extension of the technology acceptance model: Four longitudinal field studies. Management Science, 46(2), 186-204. https://doi.org/10.1287/mnsc.46.2.186.11926

Venkatesh, V., Morris, M. G., Davis, G. B., \& Davis, F. D. (2003). User acceptance of information technology: Toward a unified view. MIS Quarterly, 27(3), 425-478. https://doi.org/10.2307/30036540

Ward, A. L., Sanjak, M., Duffy, K., Bravver, E., Williams, N., Nichols, M. \& Brooks, B. R. (2010). Power wheelchair prescription, utilization, satisfaction, and cost for patients with amyotrophic lateral sclerosis: Preliminary data for evidence-based guidelines. Archives of Physical Medicine and Rehabilitation, 91(2), 268-272. https://doi.org/10.1016/j. apmr.2009.10.023

Washbourn, R., Levack, W. M., Graham, F., \& Currey, N. (2016). Te Vaerua community rehabilitation service: A participation action research study of community based rehabilitation in the Cook Islands. New Zealand Journal of Physiotherapy, 44(2), 97-104. https://doi.org/10.15619/NZJP/44.2.05
Wikström-Grotell, C., \& Eriksson, K. (2012). Movement as a basic concept in physiotherapy - A human science approach. Physiotherapy Theory and Practice, 28(6), 428-438. https://doi.org/10.3109/09593985.2012.692582

Willis, G. (2005). Cognitive Interviewing: A tool for improving questionnaire design. Sage.

World Health Organization. (2018). Seventy-first World Health Assembly adopts resolution on assistive technology. https://www.who.int/phi/ implementation/assistive_technology/71stWHA-adopts-resolution-onassistive-technology/en/

World Health Organization. (2008). Guidelines on the provision of manual wheelchairs in less resourced settings. https://www.who.int/disabilities/ publications/technology/English\%20Wheelchair\%20Guidelines $\% 20$ (EN\%20for\%20the\%20web).pdf?ua=1

World Health Organization. (2020). Assistive technology. https://www.who. int/news-room/fact-sheets/detail/assistive-technology 